Volume 9, No.3, May - June 2020

International Journal of Advanced Trends in Computer Science and Engineering

Available Online at http://www.warse.org/IJATCSE/static/pdf/file/ijatcse29932020.pdf

https://doi.org/10.30534/ijatcse/2020/29932020

\title{
Choosing an e-course architecture
}

\author{
Olga I. Vaganova ${ }^{1}$, Zhanna V. Smirnova ${ }^{2}$, Natalia V. Gorbunova ${ }^{3}$, Inna K. Kirillova ${ }^{4}$, Elena A. \\ Chelnokova $^{5}$ \\ ${ }^{1}$ Minin Nizhny Novgorod State Pedagogical University, Nizhny Novgorod, Russia, vaganova_o@rambler.ru \\ ${ }^{2}$ Minin Nizhny Novgorod State Pedagogical University, Nizhny Novgorod, Russia, \\ z.v.smirnova@mininuniver.ru \\ ${ }^{3}$ V.I. Vernadsky Crimean Federal University, Simferopol, Russia, natalya-gor2008@yandex.ua \\ ${ }^{4}$ Moscow State University of Civil Engineering, Moscow, Russia, innes_05-81@ mail.ru \\ ${ }^{5}$ Minin Nizhny Novgorod State Pedagogical University, Nizhny Novgorod, Russia, chelnelena@ gmail.com
}

\begin{abstract}
A wide selection of software contributes to the development of high-level electronic courses. In conditions of active informatization of society, it becomes necessary to choose the most effective elements for creating a course from a wide variety. The choice of the architecture of their structure is based on modern principles of their development. The article presents the principles and conditions for the development of electronic courses. The purpose of the article is to consider the technical components of the design and development of an electronic course in modern conditions. The main aspects and features of the development of electronic courses in the modern information environment are considered. Among the systems supporting the development of courses, we consider Media Transformer, Moodle, Blackboard and some others. The functionality of various electronic systems in the development of educational courses is presented. Among course editors, we consider iSpring Suite, Articulate 360, Adobe Captivate, which provide a complete set of tools for developing complex courses.
\end{abstract}

Key words: E-course, informatization, digital programs, electronic platform.

\section{INTRODUCTION}

Large-scale reform processes associated with the informatization of society's life actively influence the change in the education system. The consequence of this modernization is the strengthening of the electronic educational environment [1]. The development of electronic courses is an urgent process, allowing to expand the training opportunities of students [2].

Over the past few years, several large educational platforms [3] have appeared on the market, providing various educational courses: FutureLearn, inversity, EdX, Coursera, which provide the opportunity to study in different languages. The number of platforms is constantly expanding, and courses under development are being modernized [4].
European and American universities are leading in the number of courses being developed [5]. To maintain and improve the quality of education, it is necessary to design competitive courses [6].

\section{THEORETICAL FRAMEWORK}

The development of an electronic educational course is a complex, multifaceted process that goes through several stages.

Among them:

- course planning;

- collecting material for the development of the script and breaking it into blocks [7];

- development of facilities;

- entering course metadata;

- creation of course rules [8];

- packaging and publication of the course [9].

The choice of the most optimal format for the "packaging" of the course is the most pressing problem. The developer must choose either a remote or a mixed model [10]. The mixed version has a lot of supporters. D. Leakey considers her the most effective at the moment. B. Tomlinson supports the point of view of D. Leakey and considers blended learning the most acceptable option.

When designing an electronic training course, such technologies are used as: a high-level programming language in conjunction with database technologies [11]; hypertext technologies; design using specialized tools [12].

High-level programming languages are implemented as a software package and represent a separate executable module [13], which provides access to didactic materials in databases [14]. As a rule, this product has a high degree of replication (degree of protection) [15]. The use of high-level programming languages (for example, OjectPascal) and database management systems helps to solve many problems and translate any ideas into the design of an electronic course. Among the benefits of OjectPascal and Delphi:

- clear syntax;

- availability of IDEs;

- minimum time spent on the development of the IDE and the creation of application applications [16]. 
OjectPascal provides a constant program interface (window view, the layout of elements inside it, and more) [17].

To create an up-to-date electronic training course, hypertext technology provides wide opportunities [18]. When designing such a course, you can use hyperlinks [19]. In this case, the electronic training course will include a hypertext document with the possibility of using dynamic hypertext [20]. Its creation involves the use of programming languages HTML, JavaScript, Perl, PHP. Designing an electronic course using a special tool software allows you to create a program [21] that converts materials structured for the course into the prescribed form [22].

The experience of developing electronic training materials and training computer systems contributes to the rapid creation of new versions of software [23]. Over the years, various languages and tools have been used (MS C, VisualC ++, Delphi, Java, Lotus Learning Space 5.5.1). For example, Lotus offers a ready-made software and hardware platform for deploying applications.

\section{RESULTS AND DISCUSSION}

Course developers must rely on certain rules, taking into account the specific needs of the learning process.

The main requirements we include:

- the optimality of the required memory, the correctness of the automatic installation, accessibility for a user who does not have special skills [24];

- compliance of the software product with the stated requirements [25];

- correct operation with peripheral devices [26];

- optimal organization of the interactive work of the course;

- ergonomics of the software product [27].

The architecture of the electronic course can be represented by one of several options:

- linear - topics are studied sequentially;

- branched - the concepts of the topic are not connected with each other and can be studied in any convenient sequence [28];

- combined - combines the two previous types (some concepts are chosen by the teacher himself and they are studied sequentially, the rest are studied in any order convenient for the student).

Course design also requires consideration of the aspect of the volume of material posted. The volume of material makes developers take into account the estimated time of interaction between students and the teacher. The larger and more complex the course, the more tools you need in the electronic course to organize the interaction with the teacher, to conduct consultations and a high level of development of the material. An analysis of a number of electronic courses in computer science and information technology on electronic platforms was carried out. It was found that most of the courses available are small. That is, for their development, the student does not need interaction with the lecturer and the need for communication tools practically disappears. Figure 1 presents the results of the study.

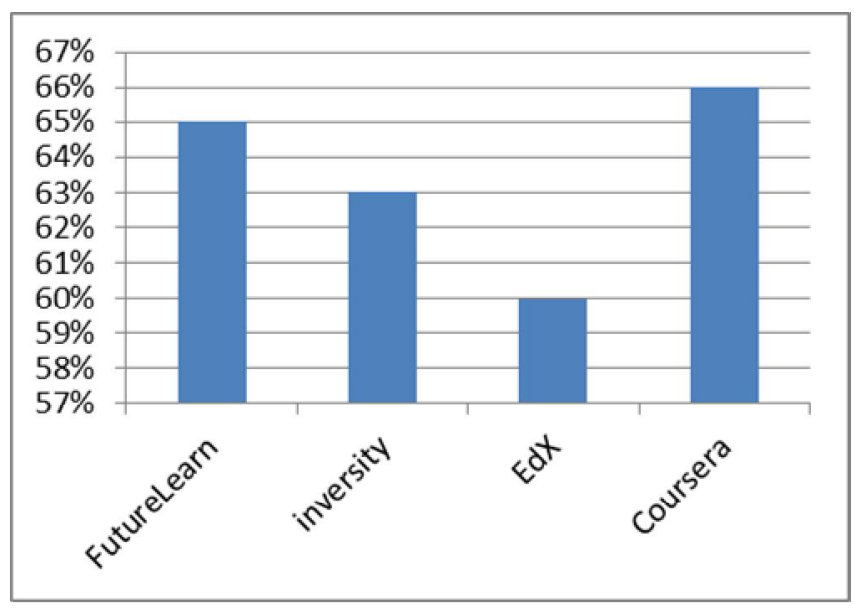

Figure 1: The number of introductory courses in computer science and information technology

After analyzing the courses on the well-known electronic platforms FutureLearn, inversity, EdX, Coursera, we can say that most often they are offered either introductory courses or courses dedicated to one small topic, so it is quite easy to master them without the support of a teacher. For example, the MiTx 6.00.1 x Introduction to Computer Science and Programming using Python courses presented on EdX.

The number of courses we study on each platform is assumed to be $100 \%$. Each of the presented electronic platforms has approximately the same number of introductory courses with a small amount of material presented for study. In other words, their study can be conducted without additional support from a teacher.

Developing courses that have a large amount of material and a high level of complexity requires more interaction with the teacher.

When designing, developers need to take this aspect into account and expand the tools that allow communication with the teacher.

Among the technologies for designing e-learning courses, it is worth noting NeoBook, which allows you to create a high-quality course, as well as interactive tests, questionnaires, questionnaires; multimedia training programs, diagnostic complexes, e-books with hyperlinks and bookmarks, illustrated databases. NeoBook has a visual interface designer, code editor, interpreter, and debugger. It allows you to use various protocols (HTTP, HTTPS, FTP, IP, UDP). it can work with folders and archives (zip, zlib, rar, cab), as well as with individual text, image, multimedia files, as well as with configuration files (for example, BAT, CMD, INI). The NeoBook language is a high-level scripting interpreted language. NeoBook allows you to create your own unique multimedia product and provides the opportunity to include it in an electronic course: 
- e-book;

- tests;

- training material;

- catalogues.

When you finish creating a product in NeoBook, you can compile the results into a standalone Windows application.

To create an application project, launch NeoBook, select the " New "command from the "File" menu section, and configure the necessary parameters. In the settings window of the new project "New Publication", select the size 640*480. Next, you need to select 16 MillionColors and standard Application (. ExE). Finish creating a new application project by clicking "Ok". For advanced settings of application parameters, select the "Project Properties" window from the Book menu. There will be 11 sections of parameters that you can access to make the necessary configuration of the application for individual needs.

In the first "General" section, type " My First publication "in the "Title" field. The author must enter their name in the "Author" field. Next, go to the Access section of the "Book properties" window. To change pages, you must allow the use of the "PageUp", "PageDown", "Home", "And" keys.

Then click " Ok" and add new pages to the app.

Popular tools from Macromedia can be used as tools for creating training materials: Authorware, Dreamweaver +CourseBuilder, Director, Flash.

Learning Space has a wide range of opportunities for developing e-courses.

- the presence of a subsystem for organizing a training course allows you to clearly plan the educational process (the calendar of the educational process acts as the center of the subsystem);

- the learning Space Toolkit contributes to the modular construction of the course;

- Courseroom creates an opportunity for active interaction between teachers and students;

- availability of a large number of supported formats (text, image, audio and video formats), their centralization, accumulation and storage on the server;

- full-text search engine;

- availability of basic high-level interaction tools;

- logical and functional interface.

Java is characterized as a simple, reliable and dynamic system. This programming language is intended for use in a network or distributed environment. It allows you to create systems that are protected from viruses and unauthorized access.

Java is architecturally neutral. The compiler generates architecturally neutral objects in the file format, which makes the compiled code executable on many processors.

Among the separate tools for creating e-learning materials, it is worth highlighting the iBooks Author program, which allows you to create books that contain not only text, but also tables, drawings, diagrams, and widgets for adding movies, control questions, photo galleries, and other multimedia elements. The program can be combined with files from Microsoft office packages. The book is created based on program templates. The completed version of the electronic textbook is saved as a *iba file for further correction. The tutorial can be exported to pdf or txt format if desired.

To create and post a course, you can use:

- Media Transformer;

- Moodle;

-Blackboard.

Moodle contains an extensive set of resources. All uploaded material is divided into didactic units. Moodle:

- has open-source code;

- focuses on collaborative learning technologies;

- provides wide opportunities for communication;

- meets the developed standards and allows you to make changes without total reprogramming;

- the style of software interfaces allows people with different levels of training to work with Moodle.

Blackboard is a single interactive environment that provides:

- create texts with different visual effects;

- use of images and any OLE objects;

- use of audio and video files;

- creating a Bank of test tasks.

Comparative characteristics of information systems for building e-courses are presented in table 1 .

Table 1: Comparative characteristics of information systems

\begin{tabular}{|l|l|l|l|}
\hline \multirow{2}{*}{ Criterion } & \multicolumn{3}{|c|}{ System } \\
\cline { 2 - 4 } & $\begin{array}{l}\text { Media } \\
\text { Transforme } \\
\text { r }\end{array}$ & Moodle & Blackboard \\
\hline $\begin{array}{l}\text { Knowledge } \\
\text { Management } \\
\text { System }\end{array}$ & - & + & + \\
\hline $\begin{array}{l}\text { Automatic } \\
\begin{array}{l}\text { Knowledge Testing } \\
\text { System }\end{array}\end{array}$ & + & + & + \\
\hline $\begin{array}{l}\text { Collection of } \\
\text { accounting and } \\
\text { learning outcomes }\end{array}$ & - & & \\
\hline $\begin{array}{l}\text { Scalability and } \\
\text { extensibility }\end{array}$ & + & + & + \\
\hline SCORM Support & - & + & + \\
\hline IMS Support & - & + & + \\
\hline
\end{tabular}

Moodle and BlackBoard have the greatest advantages in creating e-courses, expanding the training opportunities for students.

Among the course editors, we can be identified: iSpring Suite (based on PowerPoint), Articulate 360 (provides a full set of tools from long-read to the development of complex courses), Adobe Captivate (provides the creation of complex courses and allows you to adapt them for mobile devices). 


\section{CONCLUSION}

We reviewed the experience of designing and developing an e-course using various software tools. For the effectiveness of the developed course, it is necessary that it is reliable, accessible, and its interface is simple and convenient. Tools for organizing interaction between students and the teacher are important for the comfortable study of the material by students. The larger the course, the more powerful the communication elements should be. The analysis of the main aspects and features of the development of electronic educational courses in the modern information environment allows you to expand the possibilities of training students of higher educational institutions in the electronic educational environment. A comparison of the characteristics of information systems used by modern higher education institutions has shown that Moodle and BlackBoard among others have the greatest advantages in creating e-courses. Individual elements for the development of e-courses also help to complement the quality of the course. The development of an electronic course based on modern requirements makes it competitive and marketable among students.

\section{REFERENCES}

1. Pliushch, V.M. (2018). Independent work of students as a factor of improving education quality. Balkan Scientific Review, 1, 69-71.

2. Aleksieienko-Lemovska, L.V. (2019). The activity approach as a basis for preschool teachers' methodological activities, Humanitarian Balkan Research, 3, 4(6), 10-14.

3. Ilyashenko, L. K., Smirnova, Zh. V., Vaganova, O. I. Chelnokova, E. A., Kaznacheeva, S.N. (2019). Methods of Conducting Practical Training on the Subject "Power Sources for Welding", International Journal of Mechanical Engineering and Technology, 10 (02), 908-917.

4. Andriushchenko, T. K., (2018). Personal aspects of pedagogue's innovative culture, Scientific Vector of the Balkans, 1, 13-16.

5. Bakharev, N. P., (2019). Creativity - a prerequisite for the formation of professional competences in specialists of technical direction of training, Scientific Vector of the Balkans, 3, 4 (6), 17-21.

6. Cirdan, A.P. (2019). Innovative technologies of professional training of future economists in the system of continuous education. Humanitarian Balkan Research, 2(4), 27-30.

7. Filchenkova, I.F. (2019). Educational management of innovative activity of teachers as an object of pedagogical research. Vestnik Mininskogo universiteta (Vestnik of Minin University), 2019.7 (4), 3. (in Russ.).

https://doi.org/10.26795/2307-1281-2019-7-4-3

8. Myalkina, E.V. (2019). Diagnostics of the education quality in the higher educational institution. Vestnik Mininskogo universiteta (Vestnik of Minin University), 7, (3), 4. (in Russ.)

https://doi.org/10.26795/2307-1281-2019-7-3-4

9. Oros, I.I. (2018) The role of international connections in the development of the adult education system. Humanitarian Balkan Research, 1, 57-59.

10. Osadchenko, I.I. (2019). Key concepts of situational training technology in preparing future teachers. Scientific Vector of the Balkans, 1 (3), 46-49.

11. Pichugina, G.A., Bondarchuk, A.I. (2019a). Structure of the training case in the organization of the educational process. Humanitarian Balkan Research, 2(4), 5-7.

12. Pichugina G. A., Zhilyakova D. A. (2019b). Structuring the organization of the process of creativity. Scientific Vector of the Balkans, 3, 3 (5), 55-58.

13. Halatsyn, K.A., Feshchuk, A.M. (2019). Diagnosing motivational-and-valuable component of the communicative culture of students in higher technical educational institutions, Balkan Scientific Review, 3, 2 (4), 17-20.

14. Pisarenko, D. A. (2019). Evaluation of extracurricular activities of university students with a competency-based approach, Scientific Vector of the Balkans, 3, 3 (5), 37-40.

15. Vaganova, O.I., Rudenko, I.V., Markova, S.M., Smirnova, Zh.V., Kutepov, M.M. (2019b). The use of educational video materials in educational process of a higher educational institution. Amazonia Investiga, 8 (22), 216-222.

16. Grigoriev S. G., Shabunina V. A., Tsarapkina Ju. M., Dunaeva N. V. Electronic library system as a means of self-development of students of digital generation $Z$ (on the example of studying the course "Basics of the counselor activity"). Scientific and technical libraries. 2019. No. 7. Pp. 78-99. 29.

https://doi.org/10.33186/1027-3689-2019-7-78-99

17. Andrienko, O.A. (2019). Network educational technologies and their use when working with students. Humanitarian Balkan Research 2019, 1(3), 5-7.

18. Koshechko, N.V. (2018). Innovations from educational discipline "Pedagogical conflictology" in professional preparation of students. Scientific Vector of the Balkans, 1, 59-63.

19. Chirva, A.N., Chirva, O.G. (2018). Contents and method of professionally oriented training of informatic disciplines of future teachers of technologies. Scientific Vector of the Balkans, 1, 27-31.

20. Kamenez, N.V., Smirnova, Zh. V., Vaganova, O. I., Bystrova, N.V., Tsarapkina, J.M., (2019). Development of Instructing Techniques in Professional Training, International Journal of Mechanical Engineering and Technology, 10(02), 899-907.

21. Andrienko, O.A. (2019). On the need to apply gaming training technologies. Balkan Scientific Review, 2 (4), 5-8. 
22. Klinkov, G.T. (2018). The specificity of manifestation of pedagogical communication as a special construct. Scientific Vector of the Balkans, 1, 51-52.

23. Vaskovskaya, G.A. (2018). Features of implementation of pedagogical technologies of profile training. Balkan Scientific Review, 1, 76-79.

24. Vinothini K., Aida M., Heng C. Y., (2019). CodeCube: Active Learning for STEM, International Journal of Advanced Trends in Computer Science and Engineering, 8 (1.3), 293-299. https://doi.org/10.30534/ijatcse/2019/5581.32019

25. Syamsul, B. Z., Emram, Y., (2019). Perceptions of Computational Thinking in Game Based Learning for Improving Student Problem Solving Skills, International Journal of Advanced Trends in Computer Science and Engineering, 8 (1.3), 181-184. https://doi.org/10.30534/ijatcse/2019/3681.32019

26. Irwan, M. I., Siti, K., Anis, Mohd, E. I. Kamaruzzaman, I., Norazah, M. N. (2019). Impact of Games on Motivation, Attention and Skills in Pre-school Children, International Journal of Advanced Trends in Computer Science and Engineering, (2019), 8 (1.3), 157-159. https://doi.org/10.30534/ijatcse/2019/3181.32019

27. Tsarapkina, Ju.M., Petrova, M.M., Mironov, A.G., Morozova, I.M., Shustova, O.B. (2019a). Robotics as a basis for Informatization of education in children's health camp. Amazonia Investiga, 8 (20).

28. Vaganova, O.I., Ilyashenko, L.I., Smirnova, Zh.V., Bystrova, N.V., Kaznacheeva, S.N. (2019a). Students' creative abilities development in higher educational institution. Amazonia Investiga, 8 (22), 701-710 